\title{
Reported Exercise-Related Respiratory Symptoms and Exercise-Induced Bronchoconstriction in Asthmatic Children
}

\author{
Demet Inci ${ }^{\mathrm{a}, \mathrm{d}}$, Refoel Guggenheim ${ }^{\mathrm{a}}$, Derya Ufuk Altintas ${ }^{\mathrm{b}}$, Johannes H. Wildhaber ${ }^{\mathrm{c}}$, \\ Alexander Moeller ${ }^{\mathrm{a}}$
}

\begin{abstract}
Background: Unlimited physical activity is one of the key issues of asthma control and management. We investigated how reliable reported exercise-related respiratory symptoms (ERRS) are in predicting exercise-induced bronchoconstriction (EIB) in asthmatic children.

Methods: In this prospective study, 179 asthmatic children aged 7 - 15 years were asked for specific questions on respiratory symptoms related to exercise and allocated into two groups according to whether they complained about symptoms. Group I $(n=134)$ consisted of children answering "yes" to one or more of the questions and group II $(\mathrm{n}=45)$ consisted of children answering "no" to all of the questions.
\end{abstract}

Results: Sixty-four of 179 children showed a positive exercise challenge test (ECT). There was no difference in the frequency of a positive test between children in group I $(n=48)$ and group II $(n=12)$ $(\mathrm{P}=0.47)$. The sensitivity of a positive report for ERRS to predict a positive ECT was only $37 \%$, with a specificity of 0.72 .

Conclusion: According to current guidelines, the report or lack of ERRS has direct consequences on treatment decisions. However, the history of ERRS did not predict EIB and one-third of asthmatic children without complaints of ERRS developed EIB during the ECT. This raises the question of the need for objective measures of bronchial hyperresponsiveness (BHR) in pediatric asthma management.

Keywords: Exercise-induced asthma; Exercise-induced bronchoconstriction; Exercise challenge test; Children; Respiratory symptoms

Manuscript accepted for publication January 30, 2017

aDivision of Respiratory Medicine, University Children's Hospital Zurich, Steinwiesstrasse 75, 8032 Zurich, Switzerland

${ }^{b}$ Division of Paediatric Allergy and Immunology, Faculty of Medicine, University of Cukurova, 01330 Balcali, Saricam/Adana, Turkey

'Department of Paediatrics, Cantonal Hospital Fribourg, HFR 1708 Freiburg, Switzerland

${ }^{\mathrm{d} C}$ Corresponding Author: Demet Inci, University Children's Hospital, Steinwiesstrasse 75, 8032 Zurich, Switzerland. Email: demet.inci@kispi.uzh.ch

doi: https://doi.org/10.14740/jocmr2935w

\section{Introduction}

The hallmarks of asthma are chronic airway inflammation, bronchial hyperresponsiveness (BHR) and variable airway narrowing. A variety of stimuli are known to trigger bronchoconstriction in patients with asthma such as allergens, environmental irritants, cold air [1]. Approximately $80 \%$ of asthmatic children develop bronchoconstriction during or after strenuous exercise [2]. Cough, wheeze, shortness of breath and chest tightness in association with physical exercise are symptoms patients may report $[3,4]$ and in a portion of asthmatic children, these symptoms limit the ability to exercise. Unlimited physical activity is one of the key issues of asthma control as stipulated in current guidelines [5] and the evaluation of the level of asthma control is increasingly recognized as a critical aspect of the management of the disease. When assessing asthma control, physicians have to rely on the report of symptoms by the child and/or parents as patients and/ or parents do not perceive control but symptoms [6,7]. The available data on the relationship between reported exerciserelated respiratory symptoms (ERRS) such as breathlessness or dyspnea and the magnitude of bronchoconstriction after an exercise test in the laboratory are very controversial. Some authors have shown that ERRS are predictive for exerciseinduced bronchoconstriction (EIB) [8,9], whereas others found no or a poor relationship between the reported ERRS and the results of specific exercise testing [10-14]. Several recent studies have shown a poor predictive value for the asthma control test (ACT) or the asthma control questionnaire (ACQ) in predicting EIB in asthmatic children with a high percentage of children showing a positive EIB test despite reporting well-controlled asthma according to the ACT or ACQ [15-17]. One factor confounding these relationships is that the symptoms reported in EIB are similar to symptoms of exercise intolerance secondary to poor cardiovascular conditioning, obesity, and vocal cord dysfunction, among others [18]. As EIB is an index of BHR in asthma, the objective assessment of EIB by means of a formal exercise test may therefore lead to a more appropriate evaluation of asthma control [19].

The aim of this study was to investigate the frequency of EIB in children treated according to current treatment guidelines [20] and to assess differences between children reporting symptoms during physical activity and those not reporting any 
ERRS.

\section{Materials and Methods}

\section{Subjects}

In this prospective, non-randomized study, 179 consecutive asthmatic children ( 73 females, aged $10.6 \pm 2.6$ years (mean \pm SD)) were recruited from the Allergy and Asthma Outpatient Clinic of Cukurova University, Adana, Turkey over the period of 1 year. All patients had a previous asthma diagnosis, confirmed by one of the attending respiratory physicians according to international guidelines [20].

At the time of a scheduled visit, patients were invited to participate in the study and upon agreement, informed consent was obtained from parents and children, where appropriate. All patients had clinically stable asthma without emergency visits, hospitalizations or oral systemic corticosteroid use in the 3 months prior to the exercise test.

Additional exclusion criteria were: loss of asthma control requiring change of treatment and/or use of short-acting betaagonists on an as needed basis of $\geq 3$ times a week and/or a respiratory tract infection within the previous eight weeks, known chronic lung diseases other than asthma, cardiac disease and neuromuscular or orthopedic co-morbidities, that precluded adequate exercise testing or inability to perform reproducible lung function.

Five questions regarding specific exercise-related asthma symptoms in the previous 8 weeks were asked to all patients (Table 1).

Somewhat technical terms such as wheezing and dyspnea were explained to patients and parents in lay language as usually done in the clinics. Wheezing was explained as a whistling expiratory noise and dyspnea as difficulty in breathing or shortness of breath. Children were always asked if they understood all questions and more detailed explanations were given when needed. In addition, skin prick tests (SPTs) were performed. All of the subjects were invited to perform a treadmill exercise challenge test (ECT) within the following week which was conducted by an investigator (DI) who was blinded to any clinical information. Parents and patients were instructed to withhold short- and long-acting beta-2-agonists for at least $24 \mathrm{~h}$ and leukotriene receptor antagonists for 7 days prior to the test date.

The study was approved by the local ethics committee and parental consent was obtained for all study participants.

\section{ECT and lung function evaluation}

Following suitable instruction, baseline spirometry was performed (model Masterlab, Jaeger, Wuerzburg, Germany) while seated and wearing nose clips. The best forced expiratory volume in $1 \mathrm{~s}\left(\mathrm{FEV}_{1}\right)$ value of three maneuvres was expressed as percentages of reference values reported by Zapletal et al corrected for age, sex, and height [21]. The ECT was performed if $\mathrm{FEV}_{1}$ was $>75 \%$ of predicted values.

After detailed explanation of the procedure, ECT was per-
Table 1. Questions That Were Asked to the Children for Exercise-Related Symptoms

\begin{tabular}{ll}
\hline Q1 & Do you have cough during or after exercise? \\
Q2 & Do you have wheezing during or after exercise? \\
Q3 & Do you have dyspnea during or after exercise? \\
Q4 & Do you have chest tightness during or after exercise? \\
Q5 & Do you have chest pain during or after exercise? \\
\hline
\end{tabular}

formed according to American Thoracic Society guidelines [22]. The laboratory was air-conditioned $\left(19-21^{\circ} \mathrm{C}\right.$; relative humidity $<50 \%$ ). Children were exercised on a computer-controlled motor-driven treadmill (Tunturi ${ }^{\circledR}$ T-Track Gama 300 Treadmill, Turku, Finland). A technician and physician in attendance were immediately available with resuscitation equipment. Heart rate was monitored using Polar Electro 31 Coded (Polar Electro OyProfessorintie 5, Kempele, Finland).

During the first $2 \mathrm{~min}$ of exercise, treadmill slope progressively increased to $10 \%$ and speed was gently increased until the subject reached $85 \%$ of maximal heart rate for age (220 age (years)). This exercise load therefore continued for $6 \mathrm{~min}$, adjusting the speed to maintain the required heart rate.

Spirometry was repeated $1,5,10,15,30,45$, and $60 \mathrm{~min}$ after the exercise challenge. Maximum percentage fall in $\mathrm{FEV}_{1}$ after the exercise test was calculated as: (pre-exercise $\mathrm{FEV}_{1}$ minimum post-exercise $\mathrm{FEV}_{1}$ )/pre-exercise $\mathrm{FEV}_{1} \times 100 \%$. A positive response was defined by a fall in post-exercise $\mathrm{FEV}_{1}$ of $\geq 15 \%$ from baseline.

\section{SPTs}

SPT was performed on the volar surface of one forearm with common allergens including house dust mites, aspergillus mix, tree mix, grass mix, and fungi (alternaria and cladosporium), and cockroach (ALK-Abello, Horsholm, Denmark). A positive SPT was defined as a wheal with a mean diameter of at least 3 $\mathrm{mm}$ greater than the saline control in the presence of a positive histamine reaction after $15 \mathrm{~min}$.

\section{Statistical analysis}

Statistical analyses were performed using SPSS for Windows (IBM SPSS Statistics Version 20). Normally distributed data were presented as mean \pm standard deviation (SD). Differences between the two groups were analyzed by unpaired $t$-test. Differences in categorical variables between the two groups were analyzed by the Chi-squared test. Correlation analyses were performed using the Pearson correlation coefficient. The significance level was set for $5 \%$.

\section{Results}

According to the answers to the questions regarding ERRS, children were divided into two groups. Group I $(\mathrm{n}=134$, mean age 
Table 2. Clinical Characteristics of the Two Groups

\begin{tabular}{llll}
\hline & $\begin{array}{l}\text { Group I } \\
(\mathbf{n}=\mathbf{1 3 4})\end{array}$ & $\begin{array}{l}\text { Group II } \\
(\mathbf{n = 4 5})\end{array}$ & P value \\
\hline Age (years) & $10.6 \pm 2.46^{*}$ & $10.3 \pm 2.03$ & 0.5 \\
Gender (female/male) & $57 / 77$ & $16 / 29$ & $0.4^{\#}$ \\
\hline Baseline $\mathrm{FEV}_{1}(\%$ pred) & $96.5 \pm 12.7$ & $95.8 \pm 11.05$ & 0.7 \\
Regular ICS & $41(30.1 \%)$ & $7(15.5 \%)$ & $0.08^{\#}$ \\
LTRA treatment & $14(10.4 \%)$ & $3(6.6 \%)$ & $0.16^{\#}$ \\
Allergic sensitization & $114(85.1 \%)$ & $28(62.2 \%)$ & $0.7^{\#}$ \\
BMI $\left(\mathrm{kg} / \mathrm{m}^{2}\right)$ & $18.8 \pm 3.5^{*}$ & $17.9 \pm 3.1^{*}$ & 0.31 \\
\hline
\end{tabular}

*Mean \pm standard deviation. \#Chi-square. ICS: inhaled corticosteroids; BMI: body mass index; $F E V_{1}$ : forced expiratory volume in $1 \mathrm{~s}$; LTRA: leukotriene receptor antagonist.

$\pm \mathrm{SD}, 10.6 \pm 2.46$ years) consisted of children answering "yes" to one or more of the questions. These children are further referred as "symptomatic during exercise". Group II ( $\mathrm{n}=45,10.3$ \pm 2.03 years) consisted of children answering "no" to all of the questions. These children are further referred as "asymptomatic during exercise". Clinical characteristics are reported in Table 2.

Among the 179 children, 163 completed the exercise test reaching the target heart rate and requested time. In five children, the exercise test was stopped earlier due to the development of chest tightness or cough (three from group I and two from group II, respectively). As none of these patients showed a significant decrease in $\mathrm{FEV}_{1}$ after the ECT, the reported symptoms during the ECT were considered not being associated with EIB. These children were therefore excluded from the final analyses. Eleven children did not reach the target heart rate but were still included for analysis as they appeared to be exerting maximum effort while running with $15 \%$ fall in $\mathrm{FEV}_{1}$ (seven in group I and four in group II, respectively).

A total of 60 children (34.5\%) had a positive challenge test $\left(\triangle \mathrm{FEV}_{1} \geq 15 \%\right)$. No differences were found for the frequen- cy of a positive exercise test between children of group I and those without complaints of exercise-related symptoms (group II) $(36.6 \%$ and $27.9 \%$, respectively; $\mathrm{P}=0.34)$. The maximal fall in $\mathrm{FEV}_{1}$ was similar in both groups $(\mathrm{P}=0.13)$ and the time to maximal fall in $\mathrm{FEV}_{1}$ after exercise was not different in the symptomatic and asymptomatic subjects $(\mathrm{P}=0.24)$ (Fig. 1).

During the exercise test, 20 (11.4\%) children developed symptoms such as breathlessness, cough, wheezing, chest pain or tiredness, with no differences between the two groups $(\mathrm{P}=$ 0.78) (Table 3).

In order to investigate for age as a confounder of the results, hence to test the reliability of the history taken from the children, we separately analyzed the children under 11 years of age (group I: $n=70$; group II: $n=27$ ) and above 11 years (group I: $n=61$; group II: $n=16$ ). Age had no significant effect on the results $(\mathrm{P}=0.6$ and $\mathrm{P}=0.7$ for age groups $<11$ years and $\geq 11$ years, respectively).

Baseline treatment did not influence these results to a significant extent. There was no relationship between inhaled corticosteroid (ICS) use $(\mathrm{P}=0.78)$, ICS dose $(\mathrm{P}=0.6)$, the use of a leukotriene receptor antagonist (LTRA) $(\mathrm{P}=0.16)$ or a combined ICS and LTRA treatment $(\mathrm{P}=0.3)$ and the results of the test, nor any significant correlation between ICS use $(\mathrm{P}=$ $0.57)$ or ICS dose $(P=0.96)$ and maximal fall in $\mathrm{FEV}_{1}$.

Allergic sensitization was not associated with a higher degree of EIB ( $\mathrm{P}=0.3$ and $\mathrm{P}=0.78$ for a positive exercise test and maximum fall in $\mathrm{FEV}_{1}$, respectively).

The sensitivity and specificity of reported exercise-related symptoms to predict a positive test were rather low $(0.37$ and 0.72 , respectively). Whereas the positive predictive value was $80 \%(0.8)$, there was a very low negative predictive value $(0.27)$.

\section{Discussion}

We have shown that the report of ERRS does not reliably pre-

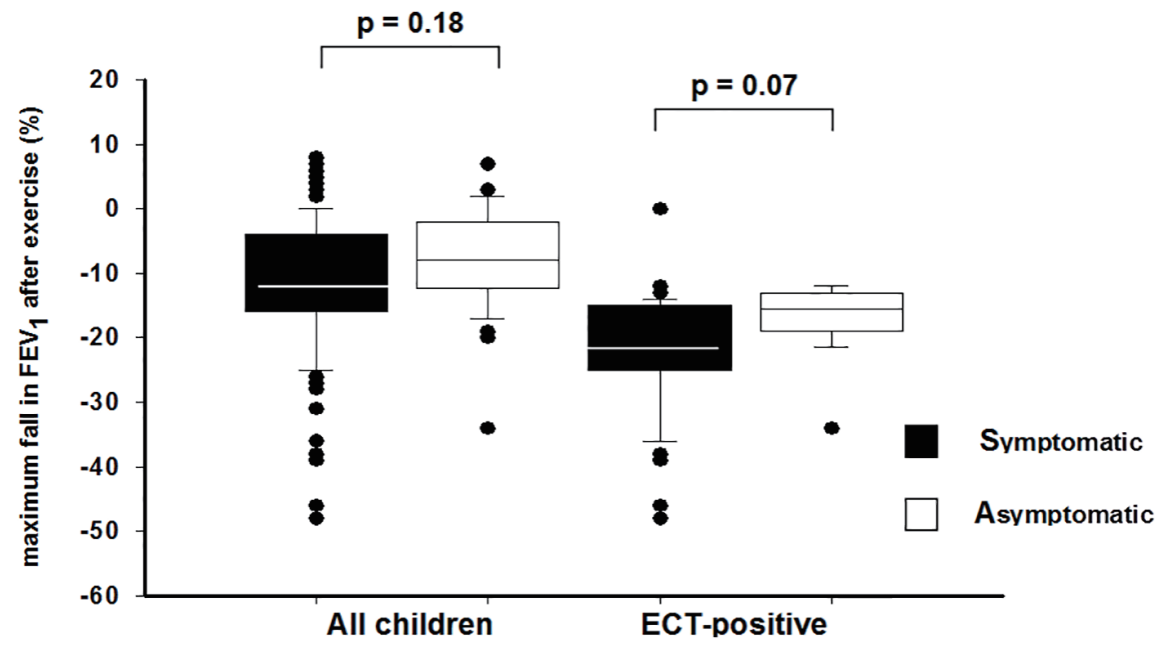

Figure 1. Box plots show the maximum fall in $\mathrm{FEV}_{1}$ after exercise challenge test between symptomatic and asymptomatic children. The median is the line bisecting the box, the box limits represent 25 th and 75th percentiles, and whiskers extend to the 10th and 90 th percentile. The black dots represent outliers. $\mathrm{FEV}_{1}$ : forced expiratory volume in $1 \mathrm{~s}$. 
Table 3. Changes in $\mathrm{FEV}_{1}$ Values After Exercise Challenge, Frequency of Symptoms and Positive ECT in Two Groups

\begin{tabular}{|c|c|c|c|}
\hline & Group I $(n=131)$ & Group II $(n=43)$ & P value \\
\hline Maximum $\%$ fall of $\mathrm{FEV}_{1}$ & $-11.09 \pm 10.5^{*}$ & $-8.11 \pm 7.7$ & 0.123 \\
\hline Positive ${ }^{\S}$ & $-22.1 \pm 8.5$ & $-16.9 \pm 5.64$ & 0.055 \\
\hline Negative & $-4.72 \pm 4.73$ & $-4.3 \pm 4.6$ & 0.54 \\
\hline \multicolumn{4}{|l|}{ ECT } \\
\hline Positive $^{\S}$ & $48(36.6 \%)$ & $12(27.9 \%)$ & $0.34^{\#}$ \\
\hline Negative & $83(63.4 \%)$ & $31(72.1 \%)$ & \\
\hline \multicolumn{4}{|l|}{ Time to maximum fall $\mathrm{FEV}_{1}$} \\
\hline $1-5 \min$ & $29(58 \%)$ & $5(31.1 \%)$ & \\
\hline $10-15 \min$ & $10(20 \%)$ & $7(35.7 \%)$ & $0.24^{\#}$ \\
\hline $30-60 \min$ & $11(22 \%)$ & $2(14.3 \%)$ & \\
\hline Symptoms during ECT ${ }^{\$}$ & $15(11.4 \%)$ & $5(11.6 \%)$ & $0.8^{\#}$ \\
\hline
\end{tabular}

${ }^{*}$ Mean \pm standard deviation. ${ }^{\#}$ Chi-square. ICS: inhaled corticosteroids; ECT: exercise challenge test. ${ }^{\S}$ Fall in post-exercise $\mathrm{FEV}_{1}$ of $\geq 15 \%$ from baseline. ${ }^{\$}$ Breathlessness, cough, wheezing, chest pain or tiredness.

dict EIB assessed by a formal ECT. One-third of asthmatic children with no complaints of ERRS developed significant EIB and almost two-thirds reporting symptoms during physical activity had a negative exercise challenge.

The degree of asthma control at any particular time period has been recognized as a critical aspect of the management of asthma. Unlimited exercise capability is an important part of asthma control. Several instruments have been developed and validated to evaluate asthma control including the ACQ [23], the asthma control scoring system (ACSS) [24], the ACT [19], the latter being adapted for its use in children [25] and the asthma therapy assessment questionnaire (ATAQ) [26]. The specific domains for exercise limitation or exercise-related symptoms of these questions are summarized in Table 4.

All these instruments including the GINA [20] guidelines comprise a domain for exercise limitation and/or exercise-related symptoms. In addition, questions on exercise limitation and ERRS are part of the asthma quality of life questionnaires [27]. With the exception of the ATAQ [26], the item regarding symptoms or limitation during physical activity is somewhat unspecific and limited to the question of exercise or activity limitation. In our study, we aimed to assess whether or not specific questions on ERRS are predictive of EIB, rather than the more general asthma control. Several recent studies evaluated the performance to predict EIB of some of the abovementioned instruments in asthmatic children. Rapino et al found a similar percentage of EIB in children with complete, partial or poor asthma control according to the ACT, i.e. $36 \%$ of children that report complete asthma control develop EIB during a treadmill exercise challenge [17]. Madhuban et al found no relationship between the categorical ACQ and the occurrence of EIB and a positive challenge test in $41 \%$ of asthmatic children reporting well-controlled asthma according to the ACQ [16]. In another study, Rapino et al showed that the ATAQ reflected EIB better than the ACT; however, the authors concluded that both the ATAQ and the ACT were insufficient to fully evaluate asthma control in children [15]. In contrast, Chinellato et al showed a moderately good discrimination power of the total ACT score in relationship to EIB [28], and interestingly that the questions on nocturnal symptoms were better related to EIB than the questions on ERRS. A reason for the inability of these instruments to predict EIB in asthmatic children could be that the questions on ERRS may be relatively unspecific and too general or that the children and/or caregiver do not relate the different questions to exercise.

Table 4. Asthma Questionnaires for Exercise Limitation or Exercise-Related Symptoms [20, 23, 24, 26, 27]

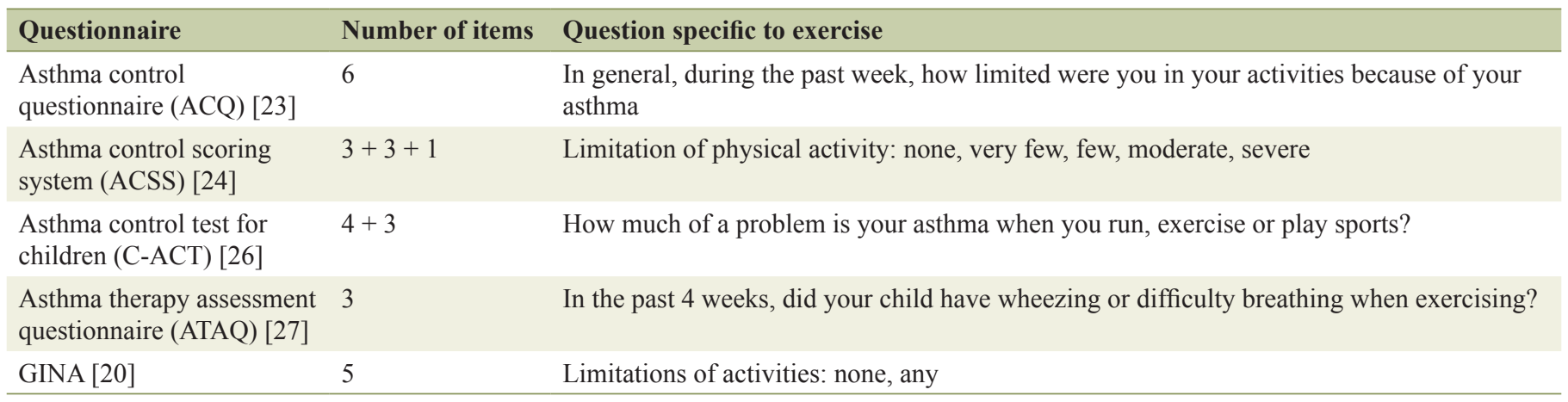


We did not apply an instrument to assess asthma control in our children, as we aimed to assess a specific history of ERRS in relation to the outcome of an ECT rather than to evaluate asthma control in general. This may be a relevant limitation of our study. The poor correlation between self-reported ERRS and the results of specific exercise tests has been shown previously and there is a rather high frequency of false positive and false negative results $[8,11-13,29,30]$. In the study by Panditi et al, the severity of ERRS during the precedent week was not related to any of the parameters of the EIB test and the parent's perception of ERRS in their children was very poorly related to the symptom perception by the children [12]. This is a very critical point, as especially in the younger children ERRS are frequently reported by the parents.

In children referred with complaints of poorly controlled exercise-induced asthma only $15.4 \%$ developed EIB in a formal exercise test [30] and EIB explained symptoms only in 11 out of 117 children who reported exercise-induced dyspnea [18]. Our results differ from the latter two studies as we included an unselected cohort of stable asthmatic children. The study by Abu-Hassan et al [18] included children referred for investigation of exercise limitation and the results are therefore not comparable to ours. In addition, we used a standard EIB-ECT and not a full ergospirometry. Therefore we are not able to exclude that some of the patients with a negative ECT but a complaint of ERRS may have suffered from co-morbidities such as inducible laryngeal obstruction (ILO), vocal cord dysfunction or physical exercise limitation.

Seasonal allergic sensitization is an important modifier of the course of asthma and hence asthma control. In our study, children were assessed consecutively over 1 year and we found no relationship between allergic sensitization as assessed by SPT, the season and the report of ERRS or the outcome of the EIB test. Similarly, previous asthma treatment did not influence the results. We cannot exclude that non-compliance or non-concordance between reported treatment and actually applied therapy influenced our findings, as treatment compliance was not objectively assessed. In our study, there were no relationship between the reports of ERRS or the results of the ECT and body mass index (BMI), but there were only few overweighed children in our cohort.

There are some limitations in our study that have to be acknowledged. First, the group of asymptomatic children was relatively small as compared to the symptomatic group. As there were no obvious trends, we are however, confident that the result would not be significantly different with more equally distributed groups.

We exercised the children aiming to achieve a heart rate of $85 \%$ of the calculated maximal heart rate as recommended by the ATS [22]. Carlsen et al have shown that an exercise load leading to heart rates of $95 \%$ of the maximal calculated heart rate results in significantly increased number of positive tests, and hence, a higher sensitivity [31]. We cannot exclude that by using a higher targeted heart rate, more children of the symptomatic group would have had a positive challenge test but this would very likely have been the same in the asymptomatic group.

What are the consequences of our results? A complaint of regular symptoms during physical activity is considered an indicator of insufficient asthma control and recent guidelines recommend treatment step up in this case [20]. Based on our and published data, there is clear evidence that exercise-related symptoms are not predictive for EIB in asthmatic children. On the other hand, there is an important portion of children developing significant EIB but do not reporting ERRS. One could argue that as long as the subject does not feel the bronchoconstriction during or after exercise, there is no need to increase treatment. There are, however two important points to be taken into consideration. One is the fact that an increasing number of children and adolescents develop a sedentary life style and may therefore not achieve exercise levels leading to significant symptoms. This will be misinterpreted as an apparent good asthma control hence treatment might be tapered down or stopped. Second, the patients could be poor perceivers of airway obstruction and therefore be at higher risk of severe asthma episodes [32]. In daily clinical life careful and precise history taking may be more realistic than performing EIB tests on a regular base for all asthmatic patients. If children complain of ERRS and there is no sufficient response to treatment and non-compliance is ruled out, former exercise tests may provide a better understanding of the etiology of their symptom and facilitate more appropriate treatment.

In conclusion, the patients' report of the existence or lack of ERRS is not reliable in predicting or ruling out EIB in asthmatic children. This finding implies a relevant challenge of the assessment of asthma control and symptom-based disease management recommended by current guidelines.

\section{Acknowledgments}

The authors gratefully thank F. Aykac, S. Erkoc, and H. Irday for providing their technical assistance with ECTs.

\section{Competing Interests}

The authors declare that they have no competing interests.

\section{Grant Support}

None.

\section{Conflicts of Interest}

All the authors have reported no conflicts of interest.

\section{References}

1. Allen TW. Return to play following exercise-induced bronchoconstriction. Clin J Sport Med. 2005;15(6):421425.

2. Nolan P. Clinical features predictive of exercise-induced asthma in children. Respirology. 1996;1(3):201-205. 
3. Storms WW. Review of exercise-induced asthma. Med Sci Sports Exerc. 2003;35(9):1464-1470.

4. Hendrickson CD, Lynch JM, Gleeson K. Exercise induced asthma: a clinical perspective. Lung. 1994;172(1):1-14.

5. Bateman ED, Hurd SS, Barnes PJ, Bousquet J, Drazen JM, FitzGerald M, Gibson P, et al. Global strategy for asthma management and prevention: GINA executive summary. Eur Respir J. 2008;31(1):143-178.

6. Kuehni CE, Frey U. Age-related differences in perceived asthma control in childhood: guidelines and reality. Eur Respir J. 2002;20(4):880-889.

7. Moeller A, Steurer-Stey C, Suter H, Hofer M, Peter M, Brooks-Wildhaber J, Hammer J, et al. Disease control in asthmatic children seen in private practice in Switzerland. Curr Med Res Opin. 2006;22(7):1295-1306.

8. Melani AS, Ciarleglio G, Pirrelli M, Sestini P. Perception of dyspnea during exercise-induced bronchoconstriction. Respir Med. 2003;97(3):221-227.

9. Turcotte H, Corbeil F, Boulet LP. Perception of breathlessness during bronchoconstriction induced by antigen, exercise, and histamine challenges. Thorax. 1990;45(12):914918.

10. Killian KJ, Summers E, Watson RM, O'Byrne PM, Jones NL, Campbell EJ. Factors contributing to dyspnoea during bronchoconstriction and exercise in asthmatic subjects. Eur Respir J. 1993;6(7):1004-1010.

11. Rundell KW, Im J, Mayers LB, Wilber RL, Szmedra L, Schmitz HR. Self-reported symptoms and exercise-induced asthma in the elite athlete. Med Sci Sports Exerc. 2001;33(2):208-213.

12. Panditi S, Silverman M. Perception of exercise induced asthma by children and their parents. Arch Dis Child. 2003;88(9):807-811.

13. Hallstrand TS, Curtis JR, Koepsell TD, Martin DP, Schoene RB, Sullivan SD, Yorioka GN, et al. Effectiveness of screening examinations to detect unrecognized exerciseinduced bronchoconstriction. J Pediatr. 2002;141(3):343348.

14. De Baets F, Bodart E, Dramaix-Wilmet M, Van Daele S, de Bilderling G, Masset S, Vermeire P, et al. Exercise-induced respiratory symptoms are poor predictors of bronchoconstriction. Pediatr Pulmonol. 2005;39(4):301-305.

15. Rapino D, Attanasi M, Consilvio NP, Scaparrotta A, Cingolani A, Cerasa M, Mohn A, et al. Evaluation of association between airway hyperresponsiveness, asthma control test, and asthma therapy assessment questionnaire in asthmatic children. Multidiscip Respir Med. 2013;8(1):48.

16. Madhuban AA, Driessen JM, Brusse-Keizer MG, van Aalderen WM, de Jongh FH, Thio BJ. Association of the asthma control questionnaire with exercise-induced bronchoconstriction. J Asthma. 2011;48(3):275-278.

17. Rapino D, Consilvio NP, Scaparrotta A, Cingolani A, Attanasi M, Di Pillo S, Verini M, et al. Relationship between exercise-induced bronchospasm (EIB) and asthma control test (ACT) in asthmatic children. J Asthma. 2011;48(10):1081-1084.

18. Abu-Hasan M, Tannous B, Weinberger M. Exerciseinduced dyspnea in children and adolescents: if not asthma then what? Ann Allergy Asthma Immunol. 2005;94(3):366-371.

19. Nathan RA, Sorkness CA, Kosinski M, Schatz M, Li JT, Marcus P, Murray JJ, et al. Development of the asthma control test: a survey for assessing asthma control. J Allergy Clin Immunol. 2004;113(1):59-65.

20. National Asthma Education and Prevention Program. Expert Panel Report: Guidelines for the Diagnosis and Management of Asthma Update on Selected Topics - 2002. J Allergy Clin Immunol. 2002;110(5 Suppl):S141-219.

21. Zapletal A, Samanek M, Paul T. Lung function in children and adolescents: methods, reference values. In: Zapletal A, editor. Progress in Respiratory Research Karger. Basel, Switzerland, 1987.

22. Crapo RO, Casaburi R, Coates AL, Enright PL, Hankinson JL, Irvin CG, MacIntyre NR, et al. Guidelines for methacholine and exercise challenge testing-1999. This official statement of the American Thoracic Society was adopted by the ATS Board of Directors, July 1999. Am J Respir Crit Care Med. 2000;161(1):309-329.

23. Juniper EF, Gruffydd-Jones K, Ward S, Svensson K. Asthma Control Questionnaire in children: validation, measurement properties, interpretation. Eur Respir J. 2010;36(6):1410-1416.

24. LeBlanc A, Robichaud P, Lacasse Y, Boulet LP. Quantification of asthma control: validation of the Asthma Control Scoring System. Allergy. 2007;62(2):120-125.

25. Liu AH, Zeiger R, Sorkness C, Mahr T, Ostrom N, Burgess $\mathrm{S}$, Rosenzweig JC, et al. Development and cross-sectional validation of the Childhood Asthma Control Test. J Allergy Clin Immunol. 2007;119(4):817-825.

26. Skinner EA, Diette GB, Algatt-Bergstrom PJ, Nguyen TT, Clark RD, Markson LE, Wu AW. The Asthma Therapy Assessment Questionnaire (ATAQ) for children and adolescents. Dis Manag. 2004;7(4):305-313.

27. Varni JW, Seid M, Rode CA. The PedsQL: measurement model for the pediatric quality of life inventory. Med Care. 1999;37(2):126-139.

28. Chinellato I, Piazza M, Sandri M, Cardinale F, Peroni DG, Boner AL, Piacentini GL. Evaluation of association between exercise-induced bronchoconstriction and childhood asthma control test questionnaire scores in children. Pediatr Pulmonol. 2012;47(3):226-232.

29. Joyner BL, Fiorino EK, Matta-Arroyo E, Needleman JP. Cardiopulmonary exercise testing in children and adolescents with asthma who report symptoms of exerciseinduced bronchoconstriction. J Asthma. 2006;43(9):675678.

30. Seear M, Wensley D, West N. How accurate is the diagnosis of exercise induced asthma among Vancouver schoolchildren? Arch Dis Child. 2005;90(9):898-902.

31. Carlsen KH, Engh G, Mork M. Exercise-induced bronchoconstriction depends on exercise load. Respir Med. 2000;94(8):750-755.

32. Bijl-Hofland ID, Cloosterman SG, Folgering HT, Akkermans RP, van Schayck CP. Relation of the perception of airway obstruction to the severity of asthma. Thorax. 1999;54(1):15-19. 